\section{Indication for delayed sternal closure}

\section{To the Editor:}

In the May 1997 issue of this Journal, Tabbutt and colleagues $^{1}$ reported an interesting study about delayed sternal closure after infant cardiac operations. Successful sternal closure was accomplished in $89 \%$ of 158 patients. Left and right atrial pressure increased about $2 \mathrm{~mm} \mathrm{Hg}$ with delayed sternal closure. Although their study showed excellent clinical results, they failed to give the indications for delayed sternal closure because the study was retrospective.

A previous prospective study published by my colleagues and $\mathrm{me}^{2}$ suggested criteria for delayed sternal closure. The study, carried out between August 1989 and July 1991, comprised 201 patients. Sternal closure was delayed when mean left atrial or central venous pressure persistently increased $2 \mathrm{~mm} \mathrm{Hg}$ or more above the initial value at the tentative sternal closure. In seven patients including six adults and only one infant, delayed sternal closure was performed, and all the patients underwent successful sternal closure $6 \pm 3$ days after the initial operation. We had no unsuccessful attempts, and catecholamine administration was maintained at a similar level to presternal closure even after sternal closure. In addition, in no case did filling pressure increase by $2 \mathrm{~mm} \mathrm{Hg}$ or more at delayed sternal closure. No patients required sternal reopening because of hemodynamic deterioration caused by cardiac compression other than fluid or blood accumulation.

Our patient number was too small to conclude that a 2 $\mathrm{mm} \mathrm{Hg}$ or greater rise of filling pressure is a standard criterion for delayed sternal closure after cardiac operations. Tabbutt and colleagues described a $2 \mathrm{~mm} \mathrm{Hg}$ increase in left atrial pressure and right atrial pressure with delayed sternal closure. Although patient profiles were different between ours and theirs, I am concerned about reopening the sternum in patients with such an increase in filling pressure at sternal closure.

Yoshio Misawa, MD, PhD

Department of Thoracic and Cardiovascular Surgery Jichi Medical School Yakushiji 3311-1 Minami-Kawachi Tochigi, 329-04, Japan

\section{REFERENCES}

1. Tabbutt S, Duncan BW, McLaughlin D, Wessel DL, Jonas RA, Laussen PC. Delayed sternal closure after cardiac operations in a pediatric population. $\mathbf{J}$ Thorac Cardiovasc Surg 1997; 113:886-93.
2. Misawa Y, Hasegawa T, Fukushima K, Sohara Y, Katoh M, Murayama F, et al. Delayed sternal closure after cardiac surgery. J Jpn Assoc Thorac Surg 1992;40:1085-8.

$12 / 8 / 85045$

\section{Reply to the Editor:}

We appreciate Misawa's comments regarding our retrospective review of pediatric patients who have an open sternum after cardiac operations. ${ }^{1}$ We presented only postoperative hemodynamic data; in $89 \%$ of our patients the sternum was left open in the operating room, and in most it was left open without attempted closure. Thus we did not address specific hemodynamic indications for leaving the sternum open in the operating room.

We described the cases of 158 patients $(89 \%)$ who underwent successful sternal closure on mean postoperative day $3.4 \pm 1.8$. We found that patients with successful closure had a significant increase in the mean left atrial pressure from $7.7 \pm 3.4$ to $9.8 \pm 4.1 \mathrm{~mm} \mathrm{Hg}(p=$ $0.000001, n=46$ ) and in the mean right atrial pressure from $8 \pm 3.2$ to $10.1 \pm 3.3 \mathrm{~mm} \mathrm{Hg}(p=0.000001, n=$ 108). None of these closures necessitated reopening.

Our patient population, which includes primarily infants (median age 10 days and median weight $3.4 \mathrm{~kg}$ ) who have had reparative two ventricle or palliative single ventricle cardiac surgery, differs from that described by Misawa and associates. ${ }^{2}$ However, we agree with Misawa that, because of the limitations of a retrospective review, we cannot determine a specific increase in atrial pressure that will predict a successful sternal closure.

Sarah Tabbutt, $M D, P h D$

Peter C. Laussen, $M B, B S$

Departments of Cardiology and Anesthesia Children's Hospital and Harvard Medical School 300 Longwood Ave. Boston, MA 02115

\section{REFERENCES}

1. Tabbutt S, Duncan BW, McLaughlin D, Wessel DL, Jonas RA, Laussen PC. Delayed sternal closure after cardiac operations in a pediatric population. J Thorac Cardiovasc Surg 1997;113:886-93.

2. Misawa Y, Hasegawa T, Fukushima K, Sohara Y, Katoh M, Murayama $F$, et al. Delayed sternal closure after cardiac surgery. J Jpn Assoc Thorac Surg 1992;40:1085-8.

$12 / 8 / 85044$ 